\title{
Acute Intestinal Obstruction from Post Operative Adhesions in a Tertiary Health Facility, South-South, Nigeria: A one year prospective study.
}

\author{
O.E. Ngim ${ }^{1}$, J. Udosen ${ }^{2}$, A. Essiet ${ }^{3}$, S.E.E.Efem ${ }^{4}$, O.O.Bassey ${ }^{5}$. \\ Dept of Surgery, College of Medical Sciences, University of Calabar, Calabar,Nigeria
}

\begin{abstract}
Post operative adhesion is the commonest cause of intestinal obstruction in the developed world whereas obstructed/strangulated external hernias are the commonest in tropical Africa. Open abdominal or pelvic surgery is often associated with this condition. Laparoscopic surgery is said to reduce the incidence of this condition, probably because there is less tissue handling compared to open surgery. Though the initial management of adhesive bowel obstruction is conservative, surgery remains an inevitable option in some cases.The aim of this study was to see the prevalence of post adhesive acute bowel obstruction amongst causes of acute abdomen in the University of Calabar Teaching Hospital within the study period.This was a one year prospective study done in this centre. All adult patients who presented with acute intestinal obstruction to the emergency unit of the hospital were included in the study. A total of 46 patients presented with acute intestinal obstruction during the study period. Eleven (23.9\%) of this number had post operative adhesions as a cause of the obstruction and it was commoner in females than males with a ratio of almost 2:1. Acute appendicitis was the commonest surgery associated with this condition (45.5\%).
\end{abstract}

Keywords:Acute intestinal obstruction, Laparoscopic surgery, Post operative adhesions,.

\section{Introduction}

Post Operative adhesions is an important cause of acute intestinal obstruction the world over ${ }^{1-4}$. It constitutes the commonest cause of intestinal obstruction in the Western world ${ }^{1,4,12}$ but is second to obstructed/strangulated hernias as a cause of acute intestinal obstruction in tropical Africa ${ }^{2-4}$. Data from the University of Calabar Teaching Hospital on this condition is scanty, hence the need for this study. The study also aimed at determining which disease conditions were more associated with intestinal obstruction from post operative adhesions in this centre.

\section{Patients and Methods}

This was a prospective study done between November 2005 and October 2006 in the University of Calabar Teaching Hospital, Calabar, Nigeria, after due clearance from the ethical committee of the hospital.

All adult patients presenting with acute intestinal obstruction were included in the study. Information obtained from these patients including clinical evaluation, investigation results and operative findings (for those who had surgery), were entered in a proforma. The patients were studied from admission to discharge and follow up. At the end of the study period, information obtained was analyzed using Epi Info 2002 Statistics software.

\section{Results}

A total of $11(23.9 \%)$ patients were diagnosed to have acute intestinal obstruction due to post operative adhesions, out of a total of 46 patients with acute intestinal obstruction seen during the study period. Post operative adhesions were second only to obstructed/strangulated external hernias $(65.2 \%)$ as a cause of acute intestinal obstruction in adults.

There were 4 males and 7 females, giving a male to female ratio of about 1:2. The age range was $23-$ 65 years with a mean age of 42 years. Five (45.5\%) patients had previous appendicectomy, three $(27.3 \%)$ had previous gynaecological operations (Caeserean section and myomectomy), while the rest had other abdominal surgeries such as splenectomy and umbilical herniorrhaphy.

In three female patients, there was history of more than one previous surgery, (cases of Caeserean section). The majority of these patients $(63.6 \%)$ were treated surgically while the remaining four (36.4\%) were managed conservatively with satisfactory outcome.

The average duration of hospital stay for those managed conservatively was 5.6 days with a mode of 4 days and a range of $4-8$ days. A longer hospital stay was observed in those who had surgical intervention with an average of 13 days and a range $9-28$ days. Post operative surgical site infection was responsible for the long hospital stay in those cases with morbidity. Only one mortality (9\%) was recorded in this series and it 
occurred in a 30 year old female who had surgery after a failed conservative treatment. She had previously had two abdominal surgical operations (caesarean section and a laparotomy). Morbidity was essentially due to surgical site infection in $3(27 \%)$ patients. Table 1 shows a summary of the 11 patients.

\section{Discussion}

Post Operative adhesions as a cause of acute intestinal obstruction is commonest in the Western World, where abdominal operations are common ${ }^{1}$. It is the commonest cause of intestinal obstruction in developed countries ${ }^{1,12,14}$ where it constitutes $40-70 \%$ of cases ${ }^{12,14}$. In Sub-Saharan Africa, it is next to obstructed/strangulated hernias as a cause of acute intestinal obstruction ${ }^{1-3}$. Adhesions are an almost invariable consequence of abdominal and pelvic surgery ${ }^{12}$. The incidence of this condition in our environment is rising especially with industrialization.

In this study, out of 46 patients with acute intestinal obstruction from various causes, 11 (23.9\%) were due to post operative adhesions. Sule et al in Jos, Nigeria ${ }^{13}$ in their two year study, reported an average of 13.5 patients per year of such cases. This figure is close to what was obtained in this study, but Dia et al in Dakar ${ }^{6}$ had an average of 4 patients per year of acute intestinal obstruction from post operative adhesion in their series. These figures tend to agree with the relatively low incidence of this condition in developing countries as documented in the literature ${ }^{1,3}$. Pomata $\mathrm{et} \mathrm{al}$ in Italy ${ }^{5}$ reported a total of 63 patients seen with this condition over a 14 year period, giving an average of 4.5 patients per year similar to that of Dia et al. Cox et al in Australia ${ }^{9}$ in their retrospective study over a 9 year period, reported an average of 16 patients per year. Comparatively therefore, the number of patients seen in our present study, cannot be considered small.

In sharp contrast however; but consistent with the high incidence documented in the literature for developed countries ${ }^{1,2,3,4}$, Kossi et al in Finland reported 123 cases at Varsinais - Suomi hospital district in one year. Though their study did not categorically state if this figure was obtained from a single or several hospitals in the district, they concluded by saying that their figure was in agreement with the average international level obtained in the Western World.

The age range of patients in our study was $23-65$ years as against $17-84$ years reported by Dia et al in Dakar but in both studies, there was a female preponderance. Several documentation in the literature report a higher incidence in women than men probably due to previous gynaecological operations ${ }^{6,8,9,10}$. Al-Sunaidi et al noted that among gynaecological operations resulting in this condition, total abdominal hysterectomy was the commonest aetiological factor.

In our present study appendicectomy was the most common surgical operation $(45.5 \%)$ resulting in post operative adhesive acute intestinal obstruction followed by gynaecological operations with $27.3 \%$. Cox et $a l^{9}$ in Australia also noted appendicectomy $(23.3 \%)$ to be the commonest surgical operation responsible for this condition, followed by colorectal resection $(20.8 \%)$ and gynaecological surgery $(11.7 \%)$. D. Menzies and Harold Ellis ${ }^{7}$ at the Westminster Hospital as well as Kossi et al ${ }^{8}$ reported this condition to be commonest with operations involving the colon. These independent observations by workers in Australia, United Kingdom and Finland are not surprising considering the higher incidence of colorectal cancers and inflammatory bowel diseases requiring colonic surgery in the Western world ${ }^{1-3,14}$. It is not surprising therefore that no case following surgery for the above conditions was recorded in our study.

The high incidence of this condition occurring after previous appendicectomy even in this study, is a reflection of the global observation that appendicectomy is the commonest abdominal surgery the world over ${ }^{1-4}$.

We found the median interval between the previous surgery and development of bowel obstruction to be 3 years (range of within $1-7$ years of previous surgery). D Menzies and Harold Ellis ${ }^{7}$ in their series noted bowel obstruction from post operative adhesions as early as 1 month ( $0.5 \%$ of cases) after surgery whereas $\mathrm{Al}$ Sunaidi et al ${ }^{10}$ had a median interval of 4 years after total abdominal hysterectomy. Harold Ellis ${ }^{12}$ in a retrospective review of 2708 laparotomies noted that $1 \%$ of these patients required surgery for adhesive obstruction within a year of surgery with half of this occurring within the first four weeks. He also noted that the long term risk of this complication occurred up to 10 years after the initial laparotomy. It is estimated that $55-94 \%$ of patients having open abdominal or pelvic surgery have a chance of developing post operative adhesions ${ }^{7}$.

In our study, the period of hospitalization was directly related to the modality of treatment. It was shorter as expected for those managed conservatively with a mean of 5.6 days, mode of 4 and a range of $4-8$ days as against an average of 13 days with a range of $9-28$ days, for those who had surgery. Pomata et al in Italy ${ }^{5}$ reported a mean hospital stay of 4.15 days (range of $2-8$ days) in their series of those managed conservatively. This is similar to what we found. No figure was given by them for those who had surgery.

Kossi et al in Finland ${ }^{8}$ recorded a median hospital stay of 4 days in their series for those managed conservatively and 11 days (range of $2-34$ days) for those managed operatively. These figures agree with findings in the present study. However, the short hospital stay of 2 days in some patients managed operatively by Kossi et al suggest the use of minimal access procedures rather than open surgery for adhesiolysis, hence a 
short hospital stay. Their study did not state the actual surgical technique used to achieve such a short hospital stay. The long hospital stay recorded in our study was due to surgical site infection in 3 (27\%) cases, following resection and anastomosis of bowel. Similar reasons may be responsible for the long duration of 34 days in the study by Kossi et al $^{8}$.

Only $1(9 \%)$ mortality was recorded in our series and this was in the immediate post operative period, after a failed conservative treatment. This patient had previous episodes of bowel obstruction from post operative adhesions, a situation that dictated the conservative approach to management and the consequent delay in resorting to surgery. Kossi et al ${ }^{9}$ reported a mortality rate of $2 \%$ in their series while Dia et al had $13 \%$ mortality amongst cases managed surgically. Also, it is important to note that all the patients in our series had an initial period of conservative management but not exceeding 48 hours. This is in keeping with the first line treatment for this condition ${ }^{1-3,14}$.

Laparoscopic surgery is said to reduce the incidence of post operative adhesions probably because of less tissue handling with no chance of tissue dessication ${ }^{1,2}$. Though several methods to prevent post operative adhesion formation has been tried, an ideal therapy is yet to be identified ${ }^{1,2,11}$. Ahmed Shafik et al ${ }^{11}$ in Egypt have reported some success using liquid paraffin in rats but its value in humans is yet to be evaluated. The use of good surgical technique, washing of the peritoneal cavity with saline to remove clots etc, minimization of gauze contact on the bowel and covering of anastomotic sites and raw peritoneal surfaces, have also been advocated.

The medicolegal implication of this condition is grave. Apart from causing small bowel obstruction, other sequelae include female infertility, dyspareunia and increased risk of visceral injury at subsequent laparotomy or laparoscopy ${ }^{12}$.

\section{Conclusion}

Abdominal/pelvic surgeries however minor, carries a risk of post operative adhesion formation and ultimately acute intestinal obstruction. It is therefore imperative that the decision to operate should be correct. Also, meticulous tissue handling with appropriate surgical technique should be employed to minimize the risk of developing post operative adhesive acute intestinal obstruction. Laparoscopic surgery is advocated where possible as a way of reducing the rising incidence of this condition the world over.

\section{POST-OPERATIVE ADHESIONS: TABLE 1: Summary of the 11 Patients under Study}

\begin{tabular}{|c|c|c|c|c|c|c|c|}
\hline $\mathrm{S} / \mathrm{N}$ & Age (yrs) & Sex & $\begin{array}{c}\text { Socio-economic } \\
\text { Class }\end{array}$ & $\begin{array}{l}\text { Previous } \\
\text { Surgery }\end{array}$ & Mode of Treatment & $\begin{array}{c}\text { Duration of } \\
\text { hospital stay (in } \\
\text { days) }\end{array}$ & Outcome of Treatment \\
\hline 1 & 55 & F & Middle & Appendicectomy & Surgery & 12 & Full Recovery \\
\hline 2 & 51 & F & High & Appendicectomy & Surgery & 13 & Full Recovery \\
\hline 3 & 62 & F & Low & Others & Surgery & 9 & Full Recovery \\
\hline 4 & 34 & $\mathrm{M}$ & Low & Appendicectomy & Conservative & 4 & Full Recovery \\
\hline 5 & 44 & $\mathrm{~F}$ & High & Appendicectomy & Conservative & 6 & Full Recovery \\
\hline 6 & 23 & $\mathrm{M}$ & Low & Laparotomy & Conservative & 6 & Full Recovery \\
\hline 7 & 36 & F & Low & Myomectomy & Conservative & 4 & Full Recovery \\
\hline 8 & 65 & $\mathrm{M}$ & Middle & Others & Surgery & 28 & Wound Infection \\
\hline 9 & 30 & $\mathrm{M}$ & Low & Appendicectomy & Surgery & 25 & Wound Infection \\
\hline 10 & 32 & $\mathrm{~F}$ & Middle & $\mathrm{c} / \mathrm{s}$ X2 & Surgery & 30 & Wound Infection \\
\hline & 30 & $\mathrm{~F}$ & Middle & $\mathrm{c} / \mathrm{s}$ and Myomectomy & Surgery & 8 & Mortality \\
\hline 11 & $\begin{array}{l}\text { Mean age: } 42 \text { years } \\
\text { Range: } 23-65 \text { years }\end{array}$ & $\begin{array}{c}\mathrm{M}: \mathrm{F}=1: \\
2\end{array}$ & & $\begin{array}{c}\text { Previous } \\
\text { Appendicectomy: } \\
45.5 \% \text { of cases }\end{array}$ & $\begin{array}{c}\text { Surgery- } 63.6 \% \\
\text { Conservative - } \\
36.4 \%\end{array}$ & Average: 13 days & $\begin{array}{l}\text { Full recovery-63.6\% } \\
\text { Morbidity (Wound } \\
\text { infection)- }-27.5 \% \\
\text { Mortality }-9.0 \%\end{array}$ \\
\hline
\end{tabular}

\section{References}

[1] M.C. Winslet, Intestinal obstruction, in R.C.G. Russel , N.S Williams, C.K. Bulstrode (Eds), Bailey \& Love's Short Practice of Surgery, 23(London: Arnold 2000) 1064 -1065.

[2] S.B. Naaeder, J.F.K. Tandoh, Acute Intestinal Obstruction,in E.A. Badoe, E.Q. Archampong ,J.T. Da Rocha-Afodu (Eds), Principles and Practice of Surgery - including Pathology in the Tropics, 3 (Accra: Assemblies of God Literature Centre Ltd. 2000) 537-538.

[3] O.E.Ngim, The Pattern of presentation, management and outcome of acute abdomen at the University of Calabar Teaching Hospital (UCTH), Calabar: A 12-month prospective study, National Postgraduate Medical College of Nigeria Part 2 Diss.,2008.

[4] O.E. Ngim, A. Essiet , S.E.E. Efem , O.O. Bassey . Acute Intestinal Obstruction in Adults in the University of Calabar Teaching Hospital, Calabar, Nigeria. Int J. Trop Surg ,3, 2009,44-49.

[5] M. Pomata , E. Erdas , B. Casu, G. Pinna , S. Licheri et al, Small bowel obstruction caused by post operative adhesions: personal experience and review of the literature, Chir Ital,58,2006,449- 58.

[6] A. Dia , B. Fall , P. Thognon , A.K. Ndoye , M.L. Sow , A. Diop , Intestinal obstruction caused by post operative adhesions 79 cases, J de Chirurgie, 128, 1991,548-551.

[7] D. Menzies, H. Ellis. Intestinal obstruction from adhesions - how big is the problem? Ann R Coll Surg Engl,72, 1990,60 63.

[8] J. Kossi, P' Saminen, M. Laato, The epidemiology and treatment patterns of post operative adhesion induced intestinal obstruction in Varsinaissuomi Hospital District, Scan J Surg, 93,2004, 68-72. 
[9] M.R.Cox ,I.F. Gunn , M.C.Eastman , R.F. Hunt, A.W. Heinz, The Operative aetiology and types of adhesions causing bowel obstruction,ANZ J Surg, 63,2008,848 -852.

[10] Al-Sunaidi, M.D. Mohammed, M.D. Tulandi , MHCM. Adhesion related bowel Obstruction after hysterectomy for benign conditions, Obs \& Gynae J,108, 2006,1162 - 1166.

[11] A. Shafik, O. El-Sibai, A.A. Shafik, A novel method for preventing post operative adhesions in the rat model, J Gynae Surg,18, 2002,65-68

[12] H. Ellis . Medicolegal consequences of post operative intra-abdominal adhesions, J R Soc Med, 94, 2001, 331-332.

[13] A.Z. Sule, D. Bada , M.I. Nnamonu, Post operative non-adhesive mechanical intestinal obstruction: A review of seven cases, Nig $J$ Med , 18,2009, 63-67.

[14] R.S. Jones, J.A. Claridge , Acute Abdomen ,in Sabiston textbook of surgery 17(Philadelphia: Elsevier 2004)1219-1239. 